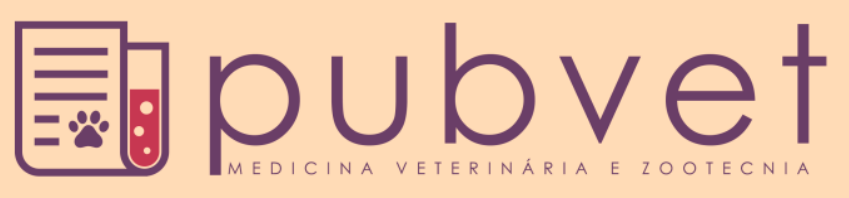

HTTP://DX.DOI.ORG/10.22256/PUBVET.V11N12.1254-1262

\title{
Biodigestão anaeróbia do bagaço da cana-de-açúcar pré-tratado e utilizando excretas de frango como inóculo
}

\author{
Samy Barros Souza Ibrahim ${ }^{1}$, Rosa Cavalcanti Lira², Elton Lima Santos ${ }^{2 *}$ Eduardo \\ Lucena Cavalcante Amorim³, Thales José de Lima Belem ${ }^{4}$, Williane Vieira Macedo5, \\ Sofia Pessoa Lira Souza ${ }^{2}$ Sarah Jacqueline Cavalcanti da Silva ${ }^{2}$, Juliana Cecilia da Silva ${ }^{4}$, \\ João Pedro Almeida Lira ${ }^{6}$
}

\footnotetext{
${ }^{1}$ Mestre em Energia da Biomassa da Universidade Federal de Alagoas, Centro de Ciências Agrárias. Rio Largo-AL, Brasil. E-mail: samybsibrahim@hotmail.com

${ }^{2}$ Professor (a) da Universidade Federal de Alagoas, Centro de Ciências Agrárias. Rio Largo-AL, Brasil.

${ }^{3}$ Professor (a) da Universidade Federal de Alagoas, Centro de Tecnologia. Maceió-AL, Brasil.

${ }^{4}$ Dicente em Zootecnia da Universidade Federal de Alagoas, Centro de Ciências Agrárias. Rio Largo-AL, Brasil.

${ }^{5}$ Dicente em Eng. ${ }^{a}$. Ambiental e Sanitária da Universidade Federal de Alagoas, Centro de Tecnologia. Maceió-AL, Brasil.

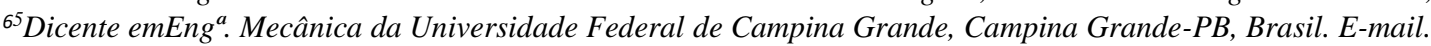

*Autor para correspondência, E-mail: elton.santos@ceca.ufal.br
}

\begin{abstract}
RESUMO. A agroindústria de cana-de-açúcar e de aves são geradoras de uma grande quantidade subprodutos que podem ter seu valor agregado potencializado quando utilizados como fonte energética. Deste modo, objetivou-se com esse estudo investigar o efeito sobre a biodigestão anaerobia do bagaço da cana-de-açúcar in natura e pré-tratado com hidróxido de sódio, utilizando-se de excretas de frango como inóculo. Para tal, utilizou-se de biodigestores experimentais de $600 \mathrm{~mL}$, com dois tratamentos: 1 - o bagaço de cana-de-açúcar inoculado com excretas de aves e 2- o bagaço de cana-de-açúcar inoculado com excretas de aves e adicionado da solução de hidróxido de sódio $(\mathrm{NaOH})$ a $4 \%$. Foram analisadas a composição química do bagaço de cana e das excretas de aves, assim também como foram avaliados os lôdos reacionais (substrato), antes e após o período de 54 dias. Analisou-se as variáveis de: $\mathrm{pH}, \mathrm{DQO}$, sólidos totais, voláteis e fixos e também a produção de gás metano $\left(\mathrm{CH}_{4}\right)$. Os resultados obtidos inferem que o tratamento em que houve pré-tratamento com hidróxido de sódio $(\mathrm{NaOH})$ a $4 \%$, apresentou melhores resultados na produção de gás metano e para os parâmetros de avaliação ambientais.
\end{abstract}

Palavras chave: biofertilizante, biogás, dejetos, energia, sustentabilidade

\section{Anaerobic biodigestion of sugarcane bagasse using chicken excreta as inoculum}

ABSTRACT. The sugar cane and poultry industry are generators of a large amount of
byproducts that can have their added value enhanced when used as an energy source. Thus,
the objective of this study was to investigate the effect on anaerobic biodigestion of
sugarcane bagasse in natura and pretreated with sodium hydroxide, using chicken excreta
as inoculum. To do this, $600 \mathrm{~mL}$ experimental biodigesters were used, with two treatments:
1 - sugarcane bagasse inoculated with bird excreta and 2 - sugarcane bagasse inoculated
with bird excreta and added $4 \%$ sodium hydroxide solution (NaOH). The chemical
composition of sugarcane bagasse and bird excreta were analyzed, as well as how the
reactive sludge (substrate) were evaluated, before and after the period of 54 days. The
variables of pH, DQO, total, volatile and fixed solids and also the production of methane
gas $\left(\mathrm{CH}_{4}\right)$ were analyzed. The results show that the treatment with $4 \%$ sodium hydroxide 
$(\mathrm{NaOH})$ pretreatment presented better results in methane gas production and environmental evaluation parameters.

Keywords: biogas, biofertilizer, waste, energy, sustainability

\section{Digestión anaeróbica del bagazo de caña de azúcar usando excrementos de pollo como inóculo}

RESUMEN. La agroindustria de caña de azúcar y de aves, son generadoras de una gran cantidad de subproductos que pueden tener su valor agregado potencializado, cuando se utilizan como fuente energética. De este modo, se objetivó con ese estudio investigar el efecto sobre la biodigestión anaerobia del bagazo de la caña de azúcar in natura y pretratado con hidróxido de sodio, utilizando excretas de pollo como inóculo. Para ello, se utilizó biodigestores experimentales de $600 \mathrm{~mL}$, con dos tratamientos: 1- el bagazo de caña de azúcar inoculado con excretas de aves y 2- el bagazo de caña de azúcar inoculado con excretas de aves y adicionada una solución de hidróxido de sodio $(\mathrm{NaOH})$ al $4 \%$. Se analizaron la composición química del bagazo de caña y de las excretas de aves, así como también se evaluaron los lodos reactivos (sustrato), antes y después del período de 54 días. Se analizaron las variables de: $\mathrm{pH}$, DQO, sólidos totales, volátiles y fijos y también la producción de gas metano $(\mathrm{CH} 4)$. Los resultados obtenidos infieren que el tratamiento en que hubo pretratamiento con hidróxido de sodio $(\mathrm{NaOH})$ al $4 \%$, presentó mejores resultados en la producción de gas metano y para los parámetros de evaluación ambiental.

Palabras clave: biogás, bio-fertilizantes, residuos, energía, sostenibilidad

\section{Introdução}

O Brasil vem buscando alternativas para o destino dos resíduos agroindustriais, adotando políticas de energia sustentável e renovável. O uso do biogás a partir da biodigestão anaeróbia uma alternativa excepcional.

Neste cenário, desponta o bagaço da cana-deaçúcar, pela agroindústria da cana-de-açúcar ser uma das mais destacadas. O Brasil teve, segundo o IBGE (2016), uma produção de 750.107.378 toneladas de cana-de-açúcar no ano de 2015. Apesar de estimar uma ligeira queda nos seus números de cultivos, cerca de $2,6 \%$.

É possível então intuir que a grande área cultivada de cana-de-açúcar gera um enorme quantitativo de resíduos, como o bagaço. Macedo (2001) estimou que as usinas de açúcar pudessem liberar de $30 \%$ a $50 \%$ do bagaço produzidos nos processos industriais da cana para serem utilizados em vias alternativas de geração de energia.

Pelizer et al. (2007) ressaltam a importância da adequação do destino para os resíduos agroindustriais. Frisa que além de criar sérios problemas ambientais, os resíduos representam perdas de matérias-primas e energia.

Da mesma forma, a avicultura nacional destaca-se a nível mundial, colocando o Brasil neste cenário como segundo maior produtor de carne de frango, produzindo 13,146 milhões de toneladas em 2016 (ANUALPEC, 2017). Em contrapartida, deve ser analisado que o país está entre os maiores geradores de resíduos provenientes desta atividade, os quais se gerenciados de forma incorreta podem acarretar em problemas ambientais e sanitários (Vacarin and Welter, 2016).

Diferentes processos biotecnológicos estão sendo desenvolvidos para transformar a matériaprima residual em bens úteis sem causar danos ao ambiente, colocando os subprodutos e emissões como insumos para outros produtos e estimulando a consciência ambiental (Wildner and Hillig, 2012).

O processo anaeróbio tem sofrido modificações nos últimos anos, mas, os estudos que visam entender as quantidades, substratos e inóculos adequados e pré-tratamentos para melhor alcançar a eficiência e a qualidade do biogás, têm sido motivos de várias pesquisas. Sendo assim, esta pesquisa objetivou avaliar a biodigestão anaerobia do bagaço de cana-de-açúcar, tratado e não tratado com hidróxido de sódio e utilizando as excretas de frango como inóculo.

\section{Material e Métodos}

O experimento foi conduzido no Laboratório de Saneamento Ambiental do Centro de 
Tecnologia (CTEC) da Universidade Federal de Alagoas (UFAL), localizado no município de Maceió, Alagoas, Brasil. A coleta do bagaço de cana-de-açúcar foi realizada na Usina de cana-deaçúcar e álcool Utinga Leão, localizada no município de Rio Largo, Alagoas, Brasil.

A amostra do material consistiu em uma quantidade aproximada de $5 \mathrm{~kg}$ de bagaço de canade-açúcar, moída pouco antes da coleta no campo, através do processo industrial de moagem para produção de etanol e açúcar da Usina de cana-deaçúcar Utinga Leão. Os tamanhos das partículas variaram de 4 a $5 \mathrm{~cm}$ e foram imediatamente armazenados em um recipiente plástico e posteriormente encaminhados ao laboratório, para o início das análises.

As excretas de frango foram obtidas do Setor de Avicultura do Centro de Ciências Agrárias da Universidade Federal de Alagoas/UFAL, localizado no município de Rio Largo/AL. Os frangos tinham até 10 dias de idade, e foram alimentados com ração à base de milho e soja. As coletas das excretas foram feitas duas vezes ao dia, durante cinco dias, e foram acondicionadas em um freezer a $0^{\circ} \mathrm{C}$.

Os biodigestores, ou seja, reatores experimentais, foi utilizada uma bateria com seis unidades de biodigestores (reatores experimentais), tipo batelada, com capacidade de $600 \mathrm{~mL}$, sendo o volume reacional correspondente a $300 \mathrm{~mL}$ de substrato e $300 \mathrm{~mL}$ de "headspace" (Figura 1). A anaerobiose foi instalada pela substituição de todo ar atmosférico presente no headspace dos reatores pelo aborbulhamento de nitrogênio.

Os reatores foram hermeticamente fechados utilizando-se uma rolha emborrachada contendo uma haste metálica, onde foi acoplada uma mangueira de silicone. A terminação da mangueira foi isolada com cola siliconada e dobrada para impedir a saída do gás que seria produzido. Os reatores foram fechados, imediatamente ao acondicionamento do material que seria fermentado, e somente foram abertos no encerramento do experimento.

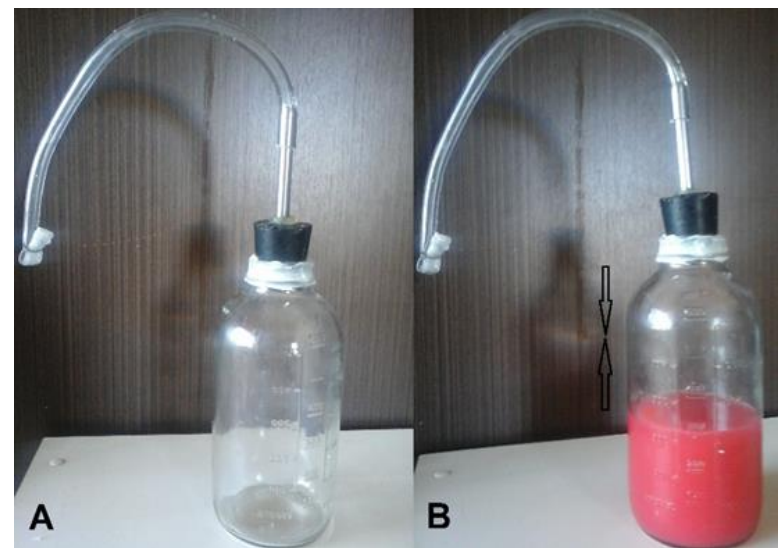

Figura 1. Reator (A) e headspace (B) dos reatores experimentais.

Foram testados dois tratamentos com três repetições. Considerou-se o bagaço de cana-deaçúcar como substrato e as excretas de frango como inóculo. O tratamento 1 consistiu em $20 \mathrm{~g}$ de bagaço de cana-de-açúcar in natura moído e desidratado, adicionado de $10 \mathrm{~g}$ de excretas de frango desidratadas e moídas e água destilada até completar $300 \mathrm{~mL}$, ou seja, $50 \%$ do volume do reator. Já o tratamento 2 foi composto pelo mesmo substrato do tratamento 1 adicionado de solução de água destilada a $4 \%$ de $\mathrm{NaOH}$, até completar $300 \mathrm{~mL}$, para corresponder da mesma forma a $50 \%$ do volume do reator, conforme descrito na Tabela 1.

Tabela 1. Descrição dos tratamentos experimentais.

\begin{tabular}{lccl}
\hline Tratamentos & Inóculo & Substrato & Água destilada \\
\hline T1R1 & $10 \mathrm{~g}$ & $20 \mathrm{~g}$ & Água destilada até $300 \mathrm{ml}$ do reator \\
T1R2 & $10 \mathrm{~g}$ & $20 \mathrm{~g}$ & Água destilada até $300 \mathrm{ml}$ do reator \\
T1R3 & $10 \mathrm{~g}$ & $20 \mathrm{~g}$ & Água destilada até $300 \mathrm{ml}$ do reator \\
T2R1 & $10 \mathrm{~g}$ & $20 \mathrm{~g}$ & Solução $4 \% \mathrm{NaOH}$ até $300 \mathrm{ml}$ do reator \\
T2R2 & $10 \mathrm{~g}$ & $20 \mathrm{~g}$ & Solução $4 \% \mathrm{NaOH}$ até $300 \mathrm{ml}$ do reator \\
T2R3 & $10 \mathrm{~g}$ & $20 \mathrm{~g}$ & Solução $4 \% \mathrm{NaOH}$ até $300 \mathrm{ml}$ do reator \\
\hline
\end{tabular}

A coleta do biogás foi feita através de uma seringa "gastight", com trava, que transpassava a mangueira de silicone implantada nos bicos dos recipientes, sendo realizado com a frequência de três dias por semana. Após a coleta o orifício 
utilizado para aspirar o gás era imediatamente fechado com cola siliconada.

A duração do experimento foi de 54 dias, durante esse período, foram aferidos os valores de $\mathrm{CH}_{4}$ (mmol.dia ${ }^{-1}$ ) produzido por cada reator experimental A temperatura do local de armazenamento dos reatores, durante todo o período de fermentação, foi mantida a $26{ }^{\circ} \mathrm{C}$, sendo controlada contra mudanças drásticas e repentinas com o acondicionamento dos reatores em uma caixa de isopor.

Foram analisados, para caracterização dos materiais utilizados como substrato e inoculo, os teores de matéria seca (MS), das cinzas, da proteína bruta $(\mathrm{PB})$ e do nitrogênio $(\mathrm{N})$ pelo método de Kjeldahl, seguindo as recomendações de Silva and Queiroz (2002).

Para a caracterização dos lodos (substratos) iniciais e finais, além dos itens anteriores, foram avaliados os sólidos totais (ST), sólidos totais voláteis (STV), sólidos totais fixos (STF), o pH, a demanda química de oxigênio (DQO) e a eficiência do DQO (APHA, 2014).

Para a avaliação dos Sólidos Totais (ST) foi aferido o peso inicial $\left(\mathrm{P}_{\mathrm{o}}\right)$ da amostra, assim que foi retirada da Mufla a uma temperatura de $550^{\circ} \mathrm{C}$, após 60 minutos. Resfriou-se essa amostra e mensurou-se o peso. Em seguida, transferiu-se para a cápsula $50 \mathrm{~mL}$ da amostra bruta, medidos em proveta de $100 \mathrm{~mL}$ e colocado em estufa a temperatura de $103^{\circ}-105^{\circ} \mathrm{C}$ durante aproximadamente 24 horas. Retirada da estufa foram colocadas em dessecador até esfriarem e a cápsula foi novamente pesada, obteve-se assim o peso seco $\left(\mathrm{P}_{1}\right)$, sendo determinados pela Equação 1 :

$\mathrm{ST}(\mathrm{mg} / \mathrm{L})=\left(\mathrm{P}_{1}-\mathrm{P}_{0}\right) \cdot 10^{6} / \mathrm{V}_{\text {Amostra }} \quad$ [Equação 1] Onde:

$\mathrm{P}_{1}$ : Peso seco

$\mathrm{P}_{0}$ : Peso inicial

V: Volume

Já para a análise dos Sólidos Totais Voláteis (STV) as amostras foram retiradas da estufa e submetidas à calcinação em Mufla a $550^{\circ} \mathrm{C}$ por 60 minutos, sendo retiradas e resfriadas em dessecador, pesadas em balança de precisão, e, obtendo-se assim, o peso final $\left(\mathrm{P}_{2}\right)$. Os cálculos expressos foram obtidos pela Equação 2. Já para a avaliação dos sólidos totais fixos, que é a porção do resíduo após a calcinação a $550^{\circ} \mathrm{C}$ por 1 hora, utilizou-se a equação 3 .

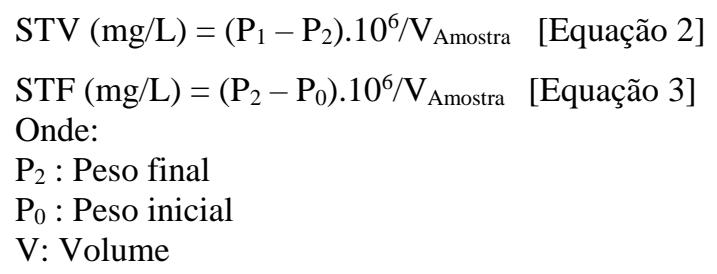

Para avaliação do pH Foi utilizado o potenciométrico com eletrodo de calomelano nas amostras iniciais e finais, ou seja, no início e no final de 54 dias. Durante todo o processo de análise não foi feita nenhuma correção de $\mathrm{pH}$. As analises para Demanda Química de Oxigênio foram feitas através do espectrofotômetro $\mathrm{HACH}$, modelo DR-2500, com comprimento de onda 620 $\mathrm{nm}$, após a digestão da matéria orgânica a $150^{\circ} \mathrm{C}$ por 120 minutos.

Para a avaliação da produção de biogás e do gás metano $\left(\mathrm{CH}_{4}\right)$ foi utilizada a metodologia aplicada por Maintinguer et al. (2008) utilizandose para a determinação da produção e composição do biogás produzido o Cromatógrafo Gasoso Shimadzu GC-2010-Plus ${ }^{\circledR}$. O aparelho possui detector de condutividade térmica, e coluna Supelco Carboxen 1010 Plot $^{\circledR}$ de $30 \mathrm{~mm}$ de comprimento e diâmetro interno de $0,53 \mathrm{~mm}$.

As coletas de biogás iniciaram-se ao quinto dia após o fechamento dos reatores. Foram realizadas a análise descritiva de todos os resultados obtidos.

\section{Resultados e Discussão}

Quanto à caracterização do bagaço de cana-deaçúcar e das excretas de frangos, utilizados para abastecer os reatores, foram observados, valores distintos proteína bruta e nitrogênio, quando comparado os dois resíduos. No entanto, notou-se apenas uma diferença mais acentuada nos valores de cinzas, $20,08 \%$ e 7,36\% para bagaço de canade-açúcar e excretas de frango, respectivamente (Tabela 2).

Tabela 2. Caracterização dos materiais utilizados como substrato reacional.

\begin{tabular}{lcc}
\hline & $\begin{array}{l}\text { Excreta de } \\
\text { frango }\end{array}$ & $\begin{array}{c}\text { Bagaço de } \\
\text { cana-de-açúcar }\end{array}$ \\
\hline Matéria seca & $77,36 \%$ & $95,36 \%$ \\
Cinzas & $20,08 \%$ & $7,36 \%$ \\
Proteína Bruta & $9,68 \%$ & $9,38 \%$ \\
Nitrogênio & $1,55 \%$ & $1,50 \%$ \\
\hline
\end{tabular}

Carvalho et al. (2009) registraram os valores de matéria seca existentes no bagaço de cana-deaçúcar em $40 \%$. Resultados semelhantes foram 
observados por Carvalho et al. (2006), que registraram 40\%. Já Cândido et al. (1999), no entanto, aferiram valores de $69,6 \%$ para a matéria seca presente no bagaço da cana-de-açúcar. Essa diferença provavelmente é devido ao tipo de processamento em que a cana in natura é submetida nas diferentes usinas de moagem, ou também devido as diferentes variedades e espécies de cana-de-açúcar utilizadas.

Ao analisar as cinzas do bagaço de cana-deaçúcar, Fredericci et al. (2012) afirmam que na literatura são indicados vários teores de cinzas obtidos da queima do bagaço de cana-de-açúcar, variando de $2,4 \%$ a $10 \%$. Portanto, os valores encontrados de 7,36\%, observado na presente pesquisa, corroborando com esses autores.

Carvalho et al. (2006) observaram teores de proteína bruta de $2,3 \%$, quando caracterizou a composição química bromatológica do bagaço da cana-de-açúcar. No entanto, Cândido et al. (1999) afirmaram que considera, como nível mínimo de proteína bruta para melhor desempenho das atividades fermentativas, o valor de $7 \%$.
Os teores observados de nitrogênio foram de $1,55 \%$ e $1,50 \%$ para o inóculo de excreta de frango e o para o substrato do bagaço de cana-de-açúcar, respectivamente. Devido a teores registrados de nitrogênio semelhantes entre os resíduos, sugerese que, talvez, a necessidade das excretas de frango, como inóculo fornecedor de Nitrogênio não fosse tão necessário.

Entretanto, vale ressaltar que devido a seu alto teor de microrganismos necessários ao processo fermentativo, é importante e continuou sendo inoculado para formação dos lodos reacionais, ou seja o substrato após a mistura dos componentes. Mesmo que segundo Costa et al. (2012) destaca que a cama (excreta) de frango gerada no processo produtivo das aves demonstra ter grande potencial para a obtenção de energia com o uso de biodigestores. Analisando os lodos reacionais iniciais e finais coletados, tanto dos reatores contendo bagaço de cana-de-açúcar in natura quanto dos reatores contendo bagaço de cana-deaçúcar tratado, observou-se os seguintes resultados (Tabela 3 ).

Tabela 3. Caracterização dos lôdos iniciais e finais.

\begin{tabular}{lcccc}
\hline & \multicolumn{2}{c}{ Lodo inicial } & \multicolumn{2}{c}{ Lodo final } \\
\hline & $\begin{array}{c}\text { Bagaço de cana } \\
\text { in natura }\end{array}$ & $\begin{array}{c}\text { Bagaço de cana } \\
\text { tratado }\end{array}$ & $\begin{array}{c}\text { Bagaço de cana } \\
\text { in natura }\end{array}$ & $\begin{array}{c}\text { Bagaço de cana } \\
\text { tratado }\end{array}$ \\
\hline MS (\%) & 87,52 & 84,31 & 88,16 & 86,94 \\
Cinzas (\%) & 6,05 & 47,42 & 8,76 & 48,04 \\
PB (\%) & 6,71 & 4,89 & 7,11 & 5,93 \\
N (\%) & 1,07 & 0,78 & 1,14 & 0,95 \\
ST (mg/L) & $42.932,22$ & $96.712,30$ & $37.231,70$ & $63.871,88$ \\
STV (mg/L) & $24.902,97$ & $46.711,26$ & $34.404,52$ & $34.529,93$ \\
STF (mg/L) & $18.029,25$ & $50.001,04$ & $2.827,19$ & $29.341,95$ \\
pH & 5,09 & 13,05 & 3,60 & 13,08 \\
DQO (mg/L) & $70.148,88$ & $77.524,32$ & $26.818,17$ & $23.437,76$ \\
Eficiência DQO (\%) & - & - & 61,79 & 69,41 \\
\hline
\end{tabular}

Foi verificada uma diminuição dos sólidos totais, voláteis e fixos. Este comportamento foi constatado de forma similar, ao de outros experimentos conduzidos com diferentes insumos sendo considerado um efeito natural, do bom aproveitamento dos nutrientes pelos microrganismos numa condição de anaerobiose. Corroborando essa afirmação Souza et al. (2015) em estudos com reatores anaeróbios abastecidos com dejetos de suínos, observou também a diminuição dos valores para os três índices de sólidos. Do mesmo modo, Steil et al. (2002) analisando o uso de inóculos em digestão anaeróbia em resíduos de aves e suínos, pode verificar que também houve uma diminuição nos sólidos totais, voláteis e fixos determinados em seu experimento. Deste modo, Fukayama (2008), estudando a biodigestão anaeróbia de cama de frango feita com casca de amendoim, obteve 43,57\% de redução no teor de Sólidos voláteis na cama de $4^{\circ}$ reutilização, ou seja, em quatro ciclos de produção de aves. Ao analisar o teor de $\mathrm{pH}$ nos lodos iniciais e finais presentes nos reatores anaeróbios, foi possível observar que houve uma diminuição nos valores para os tratamentos compostos por bagaço de cana-de-açúcar in 
natura. No entanto, para os reatores abastecidos com o bagaço de cana-de-açúcar tratado com solução a $4 \%$ de $\mathrm{NaOH}$, esse índice permaneceu mais estável. Esta reação de estabilidade do pH, para o bagaço de cana-de-açúcar tratado com $\mathrm{NaOH}$, provavelmente deveu-se ao fato do bagaço de cana-de-açúcar ter sido tratado dentro do reator, no início da sua montagem. Essa ação permitiu que o ambiente reacional sofresse uma influencia direta da solução a $4 \%$ de $\mathrm{NaOH}$.

$\mathrm{O} \mathrm{pH}$ do meio anaeróbio, é uma variável que influencia diretamente na composição e sobrevivência das bactérias metanogênicas em um biodigestor, sendo inclusive fator de sucesso ou fracasso do processo de biodigestão anaeróbia para a produção de biogás. De acordo com Van Haandel and Lettinga (1994), o pH ideal para a formação do metano deve variar entre 6,0 e 8,0 . Porém, afirmam que valores abaixo de 6,0 e acima de 8,3 devem ser evitados, pois inibem as bactérias formadoras deste gás. Segundo Batista (1981), as bactérias que produzem metano sobrevivem numa faixa estreita de $\mathrm{pH}(6,5$ e 8,0). Ainda sobre $\mathrm{pH}$, para que ocorra fermentação e produção normal de biogás, é necessário que se tenha uma faixa de $\mathrm{pH}$ entre 7,0 e 8,0 (osta, 2008).

A produção metanogênica $\left(\mathrm{mmol} \cdot \mathrm{dia}^{-1}\right)$ observado em 54 dias, desde o fechamento até a abertura dos reatores, nos reatores abastecidos com bagaço de cana-de-açúcar in natura e adicionado de hidróxido de sódio, podem ser observados nas Figuras 2 e 3 ).

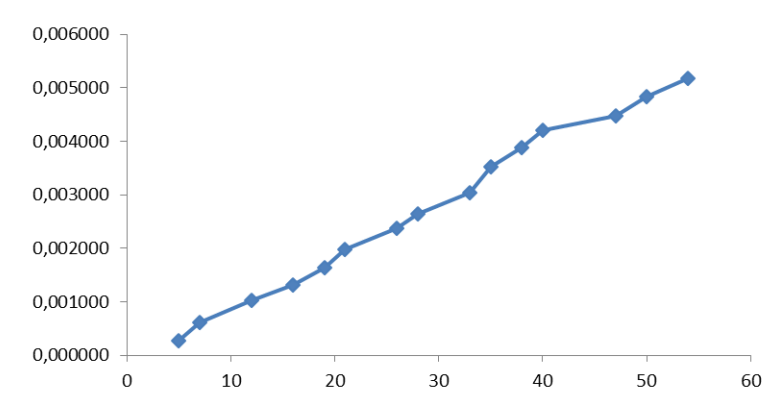

Figura 2. Produção acumulada de $\mathrm{CH}_{4}$ em mmol.dia ${ }^{-1}$, produzido pelo bagaço de cana-de-açúcar in natura por 54 dias.

Observa-se nos dados representados das figuras 2 e 3 , que nos reatores contendo bagaço de cana-de-açúcar tratado com o hidróxido de sódio $(\mathrm{NaOH})$ obteve-se, nos 54 dias analisados, uma maior produção acumulada de gás metano, $\mathrm{CH}_{4}$. (0,000494 mmol), quando comparada com os reatores contendo o bagaço de cana-de-açúcar in natura $(0,000345 \mathrm{mmol})$. Pode-se atribuir a essa diferença, a ação do hidróxido de sódio $(\mathrm{NaOH})$ na molécula de celulose e lignina, durante o processo de formação gasosa dos reatores, atuando na hidrólise do composto ligno-celulósico e agindo sobre o controle do $\mathrm{pH}$ para a manutenção de uma ação mais eficiente dos microrganismos metanogênicos. Sendo assim, visto que a lignina é uma biomolécula, não polissacarídea, de natureza hidrofóbica, que interage com a celulose e a hemicelulose. É ela a responsável pelo quase totalidade da rigidez da parede celular (Monica et al., 2009). Sendo assim, a composição da lignina pode também ter sido um possivel influenciador dos resultados obtidos.

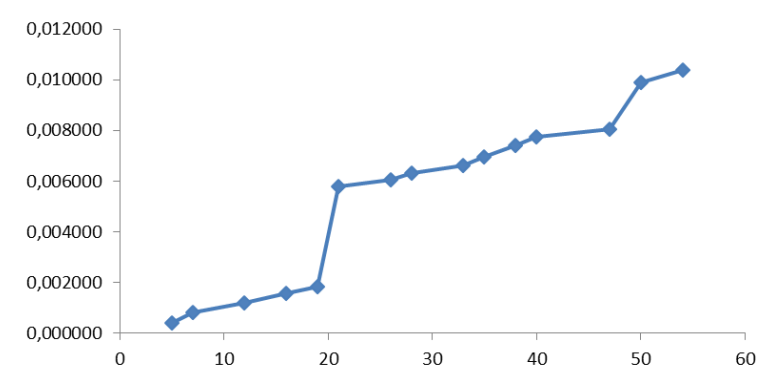

Figura 3. Produção acumulada de $\mathrm{CH}_{4}$ em mmol.dia ${ }^{-1}$, produzido pelo bagaço de cana-de-açúcar pré-tratado com hidroxido de sódio, por 54 dias.

Quando são analisados os valores da demanda química de oxigênio (DQO) no lôdo dos dois tratamentos pesquisados (Figuras 4 e 5 ), notou-se que tanto o tratamento 1 (cana in natura) quanto o tratamento 2 (adição do pré-tratamento de $\mathrm{NaOH}$ ) apresentaram valores bastante próximos, tanto para nos lôdos iniciais dos bagaços de cana-deaçúcar in natura, quanto para com o com o prétratamento (70.148,88 mg.L $\mathrm{L}^{-1}$ e 77.524,32 mg.L $\mathrm{L}^{-1}$, respectivamente), para os Lôdos finais da cana-deaçúcar in natura e tratada $\left(26.818,17 \mathrm{mg} . \mathrm{L}^{-1} \mathrm{e}\right.$ $23.437,76 \mathrm{mg} . \mathrm{L}^{-1}$, respectivamente).

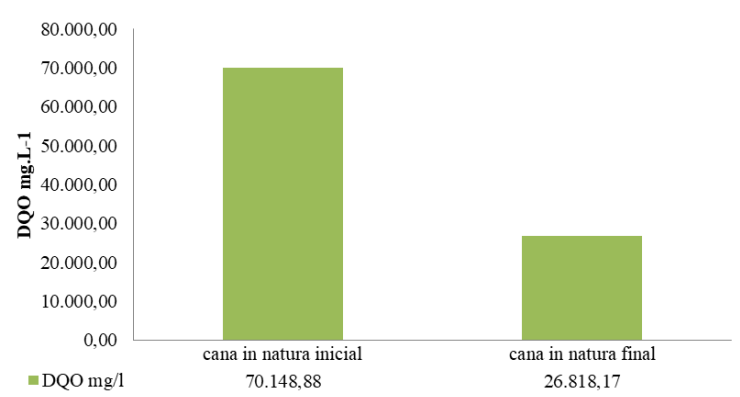

Figura 4. Demanda química de oxigênio, inicial e final, em reatores com bagaço de cana-de-açúcar in natura.

Analizando a eficiência da demanda química de oxigênio, em percentual, observouse que o tratamento 2 com bagaço de cana-deaçúcar tratado com o $\mathrm{NaOH}$ apresentaram 
melhor desempenho que o tratamento $1 \mathrm{com}$ bagaço de cana-de-açúcar in natura, registrando valores de $69,4 \%$ e $61,8 \%$, respectivamente (Figura 6).

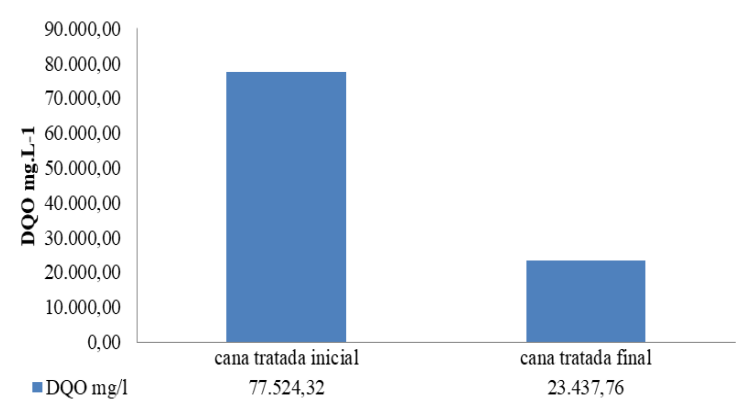

Figura 5. Demanda química de oxigênio, inicial e final, em reatores com bagaço de cana-de-açúcar tratado.

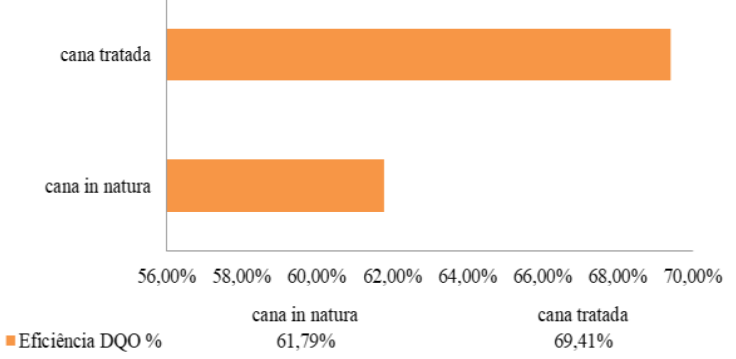

Figura 6. Eficiência na demanda química de oxigênio, em reatores com bagaço de cana-de-açúcar in natura e tratado.

Em relação à eficiência da demanda química de oxigênio, pode-se constatar uma diferença marcante quando o bagaço de cana-de-açúcar inoculado com excretas de aves foi utilizado in natura em relação ao quando foi realizado o prétratamento com hidróxido de sódio, sendo os reatores em que houve o pré-tratamento superior, da mesma forma como observado para os resultados nas figuras 4 e 5 .

O fato da interferência do pré-tratamento sobre os conteúdos não digeriveis originalmente do bagaço de cana-de-açucar é expressivo. Fato que foi também verificado por Siqueira (2015) em pesquisas com o bagaço de cana-de-açúcar submetido ao pré-tratamento com o $\mathrm{NaOH}$ em uma solução alcalina de $5 \%$, para avaliar a hidrólise da lignina e da celulose, observaram que a ação da solução empregada obteve uma elevada solubilização da lignina levando a uma melhor adsorção.

Segundo Gellerstedt (2009) as reações em meio alcalino favorecem a solubilização, uma vez que resultam na despolimerização da lignina. Em condições ácidas a condensação da lignina aumenta a sua massa molar e diminui sua solubilidade.

Há um grande potencial do uso do bagaço de cana-de-açúcar como fonte energética, através da biodigestão anaeróbia, visto que a demanda de energia elétrica no Brasil vem sendo crescente. Segundo Van Haandel and Lettinga (1994), em estudos realizados com o bagaço de cana, demonstraram ser possível apresentar uma eficiência de conversão química em elétrica variando em torno de $33 \%$ (reatores de combustão interna) e de $50 \%$ (turbinas). Outra forma ainda pouco utilizada de aproveitamento energético deste resíduo é através da digestão anaeróbia. Neste processo o bagaço tem seu material orgânico convertido em biogás. Martins (2009) considera como principal vantagem econômica, na produção de energia elétrica a partir do bagaço de cana-de-açúcar o fato desse processo se tornar uma fonte de renda, quando utilizado para a comercialização de créditos de carbono em bolsas de valores.

A co-geração de energia elétrica já é amplamente utilizada pelas usinas de cana-deaçúcar e outros setores industriais, visando, principalmente, suprir as necessidades próprias de energia. Existem usinas, inclusive, que disponibilizam o excedente de energia produzida para companhias distribuidoras de energia elétrica (Souza et al., 2015), gerando ainda mais lucros. Entretanto, esses processos necessitam ser otimizados, com técnicas que visem o máximo aproveitamento. $\mathrm{O}$ que foi demonstrado no presente estudo, que o uso de inoculo e do prétratamentos devem ser considerados, nestes procedimentos.

De modo geral, verifica-se então que a utilização do bagaço de cana-de-açúcar inoculado com excretas de aves e pré-tratado com hidrosido de sódio, pode ser uma alternativa potencial e efetiva à produção de biogas e uso do metano como fonte energética.

\section{Conclusão}

O bagaço de cana-de-açúcar inoculado com excretas de aves submetido ao tratamento com a solução de hidróxido de sódio $(\mathrm{NaOH})$ a $4 \%$, é um potencial substrato para a produção de biogás, apresentando melhores resultados para produção de gás metano $\left(\mathrm{CH}_{4}\right)$ e nos parâmetros de avaliação ambientais, quando comparado com os resultados do bagaço de cana-de-açúcar in natura. 


\section{Referências bibliográficas}

ANUALPEC. 2017. Anuário da Pecuária Brasileira, 20th edn. Instituto FNP, São Paulo, SP, Brasil.

APHA. 2014. Standard methods for the examination of water and wastewater. American Public Health Association.

Batista, L. F. 1981. Construçao e operaçao de biodigestores: modelo indiano. Séries manuais. EMBRATER.

Cândido, M. J. D., Neiva, J. N. M., Pimentel, J. C. M., Vasconcelos, V. R., Sampaio, E. M. \& Mendes Neto, J. 1999. Avaliação do valor nutritivo do bagaço de cana-de-açúcar amonizado com uréia. Revista Brasileira de Zootecnia, 28, 928-935.

Carvalho, G. G., Cavali, J., Fernandes, F. E., Rosa, L. O., Olivindo, C. S., Porto, M. O., Pires, A. J. \& Garcia, R. 2009. Composição química e digestibilidade da matéria seca do bagaço de cana-de-açúcar tratado com óxido de cálcio. Arq. bras. med. vet. zootec, 1346-1352.

Carvalho, G. G. P., Pires, A. J. V., Veloso, C. M., Magalhães, A. F., Freire, M. A. L., Silva, F. F., Silva, R. R. \& Carvalho, B. M. A. 2006. Valor nutritivo do bagaço de cana-de-açúcar amonizado com quatro doses de uréia. Pesquisa Agropecuária Brasileira, 41, 125132.

Costa, L. V. C da. 2008. Tratamento de Resíduos na Suinocultura com uso de Biodigestores. Pubvet: Publicações em Medicina Vetreinaria e Zootecnia, 2, 49, on line.

Costa, L. V.C., Sagula, A. L.; Junior, J. L. 2012. Uso de remediadores biológicos na biodigestão anaeróbia da Cama de frango de corte. Revista Brasileira de Engenharia de Biossistemas. 6, 71-78.

Fredericci, C. 2012. Caracterização de cinzas de bagaço de cana como matéria prima para a produção de cerâmica. $56^{\circ}$ Congresso Brasileiro de Cerâmica $1^{\circ}$ Congresso LatinoAmericano de Cerâmica IX Brazilian Symposium on Glass and Related Materials 03 a 06 de junho de 2012, Anais... Curitiba, PR, Brasil.

Fukayama, E. H. Características quantitativas $e$ qualitativas da cama de frango sob diferentes reutilizações: efeitos na produção de biogás e biofertilizante. 2008. 96 f. Tese (Doutorado em Produção Animal) Faculdade de Ciências
Agrárias e Veterinárias, Universidade Estadual Paulista, Jaboticabal, 2008.

Gellerstedt, G. 2009. Chemistry of chemical pulping. Pulping Chemistry and Technology, 2, 91-120.

Macedo, I. C. 2001. Geração de energia elétrica a partir de biomassa no Brasil: situação atual, oportunidades e desenvolvimento. Relatório para o MCT. Ministério de Ciência e Tecnologia, Brasília.

Maintinguer, S. I., Fernandes, B. S., Duarte, I. C. S., Saavedra, N. K., Adorno, M. A. T. \& Varesche, M. B. 2008. Fermentative hydrogen production by microbial consortium. International Journal of Hydrogen Energy, 33, 4309-4317.

Martins, R. 2009. Energia produzida a partir do bagaço de cana é economicamente viável. Agência USP. Disponível em: http//www.essentiaeditora.iff.index.br. Acesso em 18 de agosto de 2016.

Monica, E. K., Gellerstedt, G. \& Henriksson, G. 2009. Wood chemistry and biotechnology. Walter de Gruyter.

Pelizer, L. H., Pontieri, M. H. \& de Oliveira Moraes, I. 2007. Utilização de resíduos agroindustriais em processos biotecnológicos como perspectiva de redução do impacto ambiental. Journal of Technology Management \& Innovation, 2, 118-127.

Silva, D. J. \& Queiroz, A. C. 2002. Análise de alimentos: métodos químicos e biológicos, 3 edn. Universdiade Federal de Viçosa, Viçosa, Minas Gerais, Brasil.

Siqueira, G. A. 2015. Efeito da lignina de bagaços de cana-de-açúcar pré-tratados na hidrólise enzimática da celulose. 139p. Tese (Doutorado em Ciências) - Escola de Engenharia de Lorena, Universidade de São Paulo, Lorena SP.

Souza, A. C., Fugita, F. I., Sousa, A. H. \& Santos, B. D. C. 2015. Estudo das aplicações do bagaço da cana-de-açúcar dentro e fora das indústrias sucroalcooleiras. Revista Brasileira de Energia, 21, 91-115.

Steil, L., Lucas Jr., J. \& Oliveira, R. A. 2002. Avaliação do uso de inóculos na biodigestão anaeróbia de resíduos de aves de postura, frangos de corte e suínos. Engenharia Agrícola, 22, 146-159.

Vacarin, L. \& Welter, M. 2016. Estudo da gestão dos resíduos orgânicos gerados pela avicultura 
industrial no município de Caibi-SC. Revista Interativa, 2, 1-21.

Van Haandel, A. C. \& Lettinga, G. F. 1994. Tratamento anaeróbio de esgotos: um manual para regiões de clima quente. Epgraf, Campinas, Brasil.

Wildner, L. B. A. \& Hillig, C. 2012. Reciclagem de óleo comestível e fabricação de sabão como instrumentos de educação ambiental. Electronic Journal of Management, Education and Environmental Technology, 5, 813-824.

Article History:

Received 10 July 2017

Accepted 4 August 2017

Available on line 4 September 2017

License information This is an open-access article distributed under the terms of the Creative Commons Attribution License 4.0, which permits unrestricted use, distribution, and reproduction in any medium, provided the original work is properly cited 